\title{
Movie Magic Makes Better Social Robots: The Overlap of Special Effects and Character Robot Engineering
}

\author{
Derek Scherer \\ Golem Group, LLC
}

This essay provides a perspective on the ongoing convergence of social robots and special effects, animation, animatronics, puppetry techniques, and other entertainment technologies. In this paper, I will address the following design concepts:

- Character robot design principles and concepts

- Fully realized Character robots as Slaves, as a term and social artifact

- The implementation of particular special effect techniques

I abstract robots into six categories and focus the discussion on one of these: The Companion type.

I suggest that this type of robot might benefit from being what I call a Character robot, achieving this status by possessing the following four traits:

1) Biological in its appearance

2) Clear and simple in its expression

3) Well-animated

4) Recognizable in its personality

Keywords: character robot, animatronics, animation, puppets, special effects, human-robot interaction, personality, companion, slave, social robot, monster, creature, hobbit, elysium, puppetry

\section{Introduction}

Personal robots are poised to become an integral part of our daily lives, but they are still not the kind of thing that I want to interact with. They are less attractive and friendly than a kitten, less interesting than a person, and less usable than a computer. Maybe we cannot soon make a single robot that excels in all three areas, but I believe that some guidelines from the world of entertainment could lead to a more engaging type of Social robot — one for use by or with humans (Tei, 2012). This essay provides my perspective on how we, as robot engineers, designers, and scientists, can explore the 'attractive and friendly' dimension of our robots using techniques I have been exposed to through my work in film, toy, and haunted house robotic effects.

After earning engineering and science degrees and getting experience in military robotics as well as in toy and film robotics, I found a way to merge my passions for animatronic creatures and robot technology. Following a career of sufficient advancement in special effects, puppetry, animatronics, artificial intelligence, and robotics engineering (ME, EE, CS, etc.), my role is that of the designer and engineer of a large portion of responsibilities that function well for a very small subset of robots. I am the person that finds ways to integrate the art, science, and engineering of entertainment and other robotics into my own designs - often as components or primitives. This essay will also help define and explain the product of my specialty: the Character robot.

Authors retain copyright and grant the Journal of Human-Robot Interaction right of first publication with the work simultaneously licensed under a Creative Commons Attribution License that allows others to share the work with an acknowledgement of the work's authorship and initial publication in this journal. 


\section{Character Robot:}

A Social robot or Entertainment robot with which an individual has at least some moral or ethical sense or connection. The robot of discussion appears as biological, expresses itself clearly, is well-animated, and has a recognizable personality.

The four attributes at the end of that definition are at the heart of every Character and are explored in some depth throughout this essay.

\section{The Role of the Character Robot}

Regularly working with scientists, I apply various sciences to my engineering work, but this paper is not strictly about science. My purpose here is only to relate information and advance some ideas that are hopefully already recognized within the Human-Robot Interaction (HRI) community. A necessary foundation for this to happen is to first establish what kind of robots are the topic of focus in this essay.

While looking for new clients at the HRI 2011 conference, I was told by one researcher that they are not interested in what I do, because their HRI lab does not make entertainment; HRI is serious science and I was doing wrong by hustling there.

I hope the reader understands that I am not intending to force "entertainment value" on everything, nor am I implying that every Social robot should be a Character. Furthermore, I do not think that every Companion Slave needs to be a Character.

To better understand where the Character robot principles apply, I have abstracted all robots into six types.

Table 1 - The Six Types of Robot

\begin{tabular}{|c|c|}
\hline Example of Type & Definition of Type \\
\hline $\begin{array}{l}\text { Willow Garage's Personal Robot 2. Photo } \\
\text { credit: University of California-Berkeley } \\
\text { (2013). }\end{array}$ & $\begin{array}{l}\text { Work } \\
\text { This type includes industrial manufacturing } \\
\text { and other processing machinery, commercial } \\
\text { robots (which are essentially socialized } \\
\text { industrial robots), medical robots, vacuum } \\
\text { cleaner robots, etc. } \\
\text { For me, the emotional connection is low with } \\
\text { the Personal Robot } 2 \text { - despite its humanoid } \\
\text { joint placements. The work robot is mostly } \\
\text { there to do something for us-not to do } \\
\text { something with us or to us. If someone gains a } \\
\text { connection with an industrial robot, it gains } \\
\text { social status and becomes a work slave to that } \\
\text { person. }\end{array}$ \\
\hline
\end{tabular}




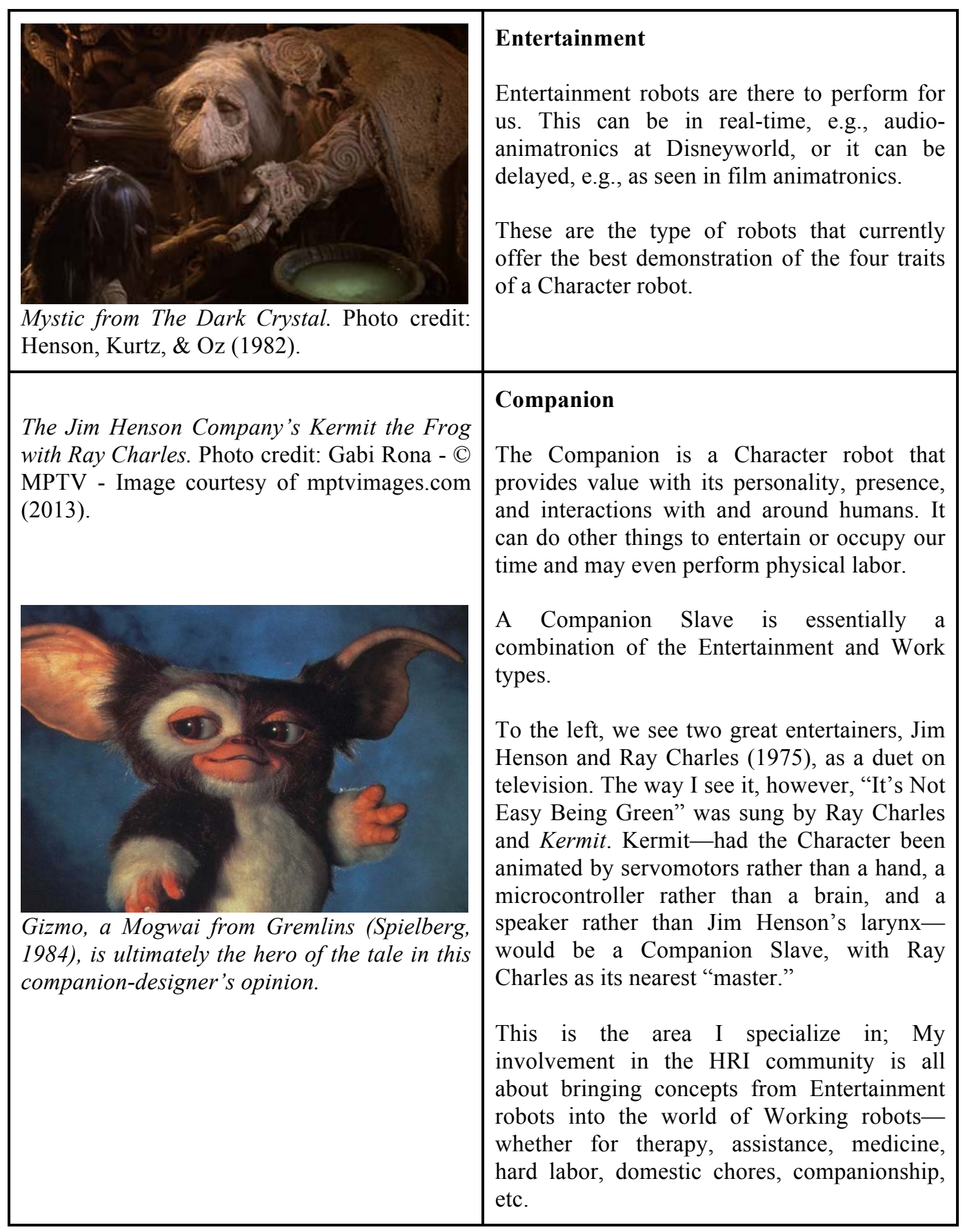




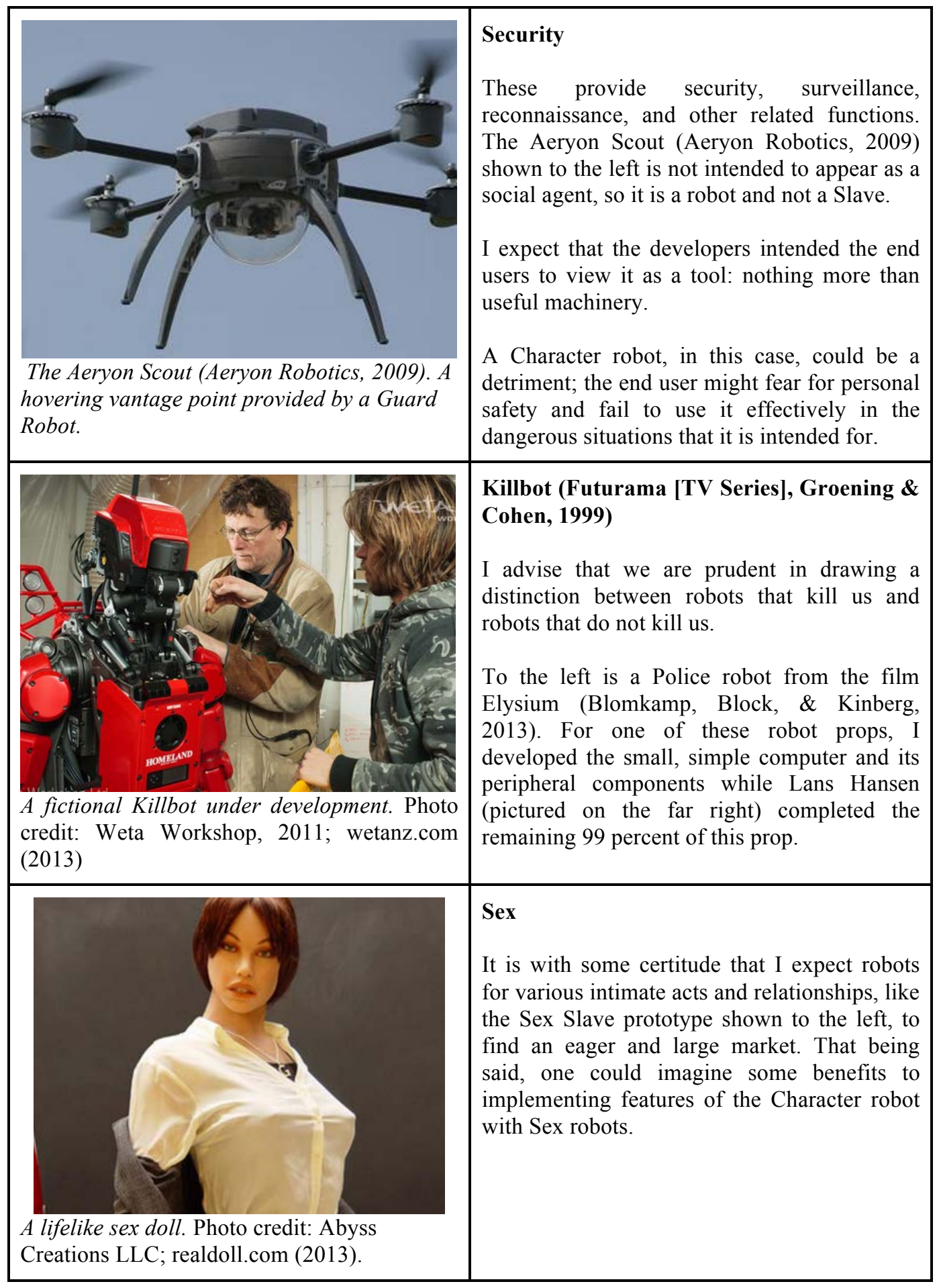


The focus of my Character robot work is in the following areas:

\section{Companion:}

A Social robot that is meant to spend time directly interacting with a person or persons in order to create strong social bonds as well as to perform some valuable function. A Character robot is well-suited for this type.

\section{Slave:}

A robot system that does valuable work without reward, and with which an individual has at least some moral or ethical sense or connection. Slaves are often Characters or Companions.

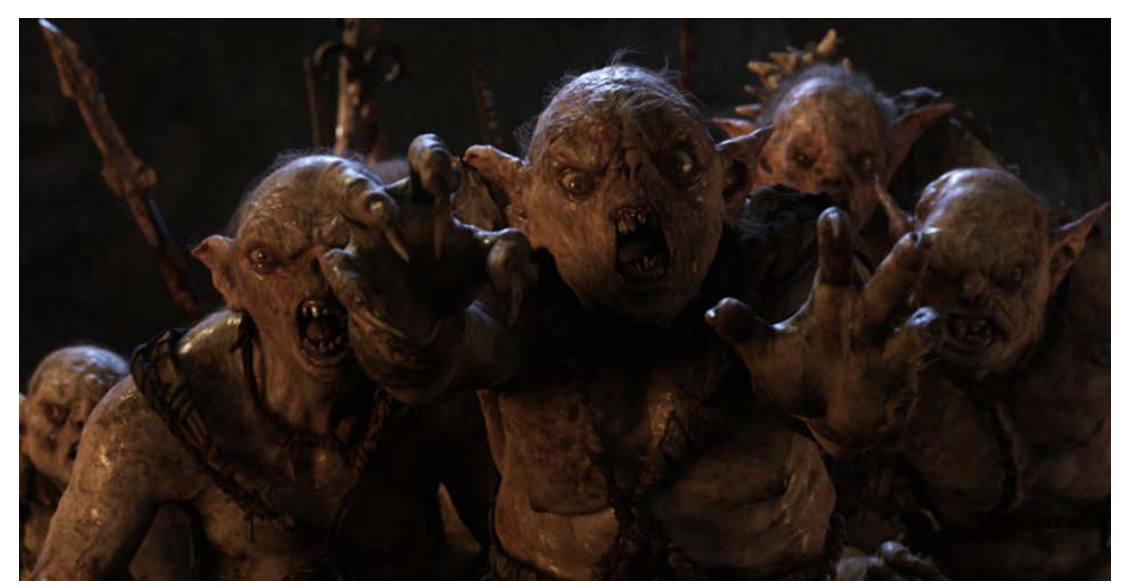

Figure 1. Computer graphics goblins from The Hobbit: An Unexpected Journey (Cunningham, Weiner, Walsh, \& Jackson, 2012).

The work that I did for The Hobbit required that each robot be perceived only as a Character. The digital creatures in Fig. 1 provide an example of how deep characterization can be, even among nasty goblins. It is because of this diversity that the technology we developed had to allow for different personality types, embodiments, etc.

The robotic creatures we develop for films are Entertainment robots while on set (and also Companion robots to the actors they interact with), but are simply Characters just like the human actors in the final film.

Slave robot cannot be used interchangeably with Social robot because not all Social robots are equally sympathetic/likable for each individual. It is actually this disparity that stimulated my interest in designing more compelling robots by making them into Characters.

When Work robots become Characters, by the definitions above, they also become Slaves. If your favorite plush stuffed animal came alive and started helping you with your household chores, your stuffed animal would now be your Slave. It may "love" working so you may not perceive any ethical issues, but you would not feel comfortable ripping your stuffed animal apart. It has a social role, by incorporating what Turkle, Taggart, Kidd, and Dasté (2006) call a "relational artifact," and is responsive to you. This may be what ethically implies that it should not be treated the same as the typical non-living object.

As an aside, you may have bristled at the usage of "slave" when describing robots that both work and socialize with us. The term is useful to describe these robots, but it also describes their role in society; when your stuffed animal came alive in the prior mental experiment, you would not soon wonder whether she should have the right to vote or whether he should be given a place at your dinner table. I have no science to back this distinction up, but this knowledge helps me design robots that inhabit these Slave social roles.

For ease of comprehension in my everyday conversation and throughout this paper, I use the generic term, "robot." Robot refers to autonomous machines in the Slave classification as well as 
all other robot entities that we do not consider social agents. It is important to recognize what can be a potential drawback: We will work with Character robots differently than non-Character robots. I believe that the advantages outweigh the disadvantages.

\section{A Muppety Mental Experiment in Character Robot Interaction}

Children may have an easier time making connections with robots (Kahn et al., 2012), so a childlike perspective and imagination might be the way to approach the problem.

I tried to imagine an ideal interaction with another creature. This mental social interaction need not be with a robot, indeed it can be with anything at all. I started my mental experiment with a friendly character that I already knew: Kermit the Frog.

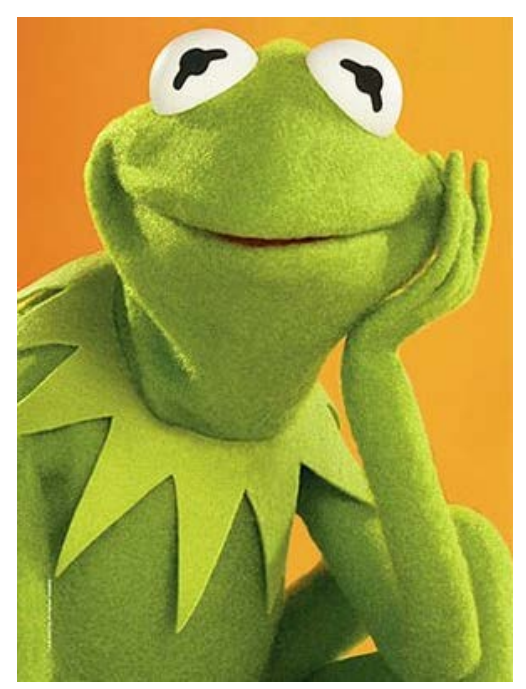

Figure 2. Kermit the Frog of the Muppets (Henson, 1976).

If you want to see what my daydream was like, then imagine a real Kermit the Frog sitting on the table in front of you. He is there. Point at him. He is talking to you in his exaggerated, Muppety way. You tell him what has been bothering you lately and he is nodding his head in agreement. He understands what you are saying. Now he is looking into the distance and sharing some ancient pond wisdom that makes a real difference in your life.

Character robot development is just various engineering and science branches mixed with entertainment technology. Special effects, puppetry, animation, and the like can create nearperfect illusions. User Experience Design and Human-Machine Interface technology have come a long way; I can ask my phone a question and get the right answer.

So why doesn't a Kermit robot exist yet?

I think it is just a matter of time. If you truly imagined Kermit saying something powerful and it had an impact on you, then you have essentially had a real interaction with a synthetic Character. Now it is a matter of making those same experiences happen using the available tools.

One fasinating aspect about modern robotics is that we are capable of implementing a huge variety of relationship schemes. Yet, much of our community seems stuck on making "robots" as we have already experienced them; robots are things that look like industrial, commercial, or medical machinery. Robots may highlight their electronic machinery, such as by using an LCD display for a face. Robots can also have exposed mechanisms because we all know they are machines, thereby certainly avoiding the Uncanny Valley (Mori, 1970). In terms of characterization, the robot face often appears like a natural evolution from a toaster. It often has a blank, non-threatening, smooth, sterile, and baby-like face. 


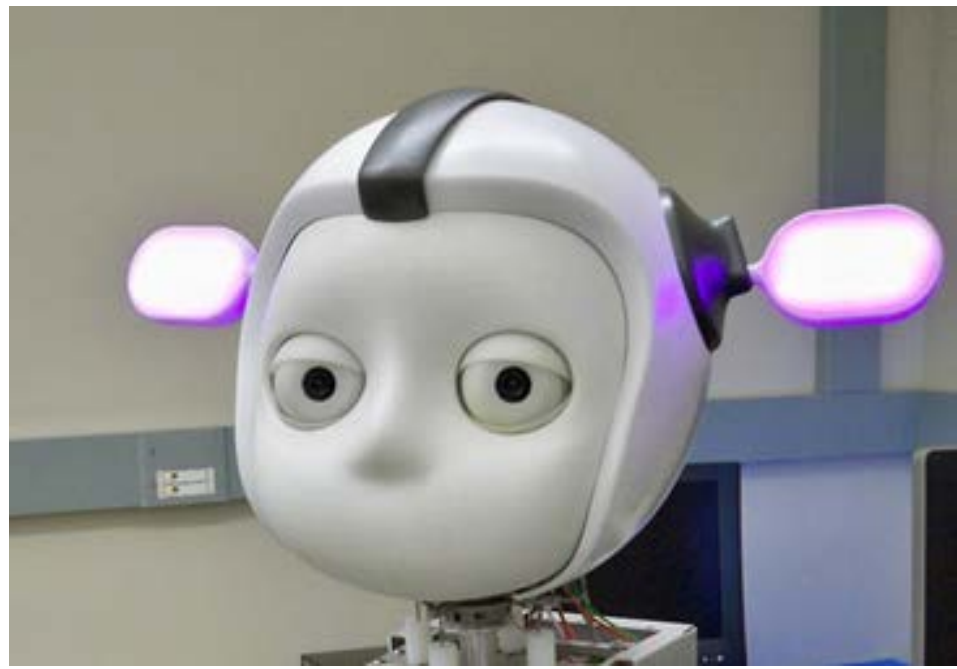

Figure 3. Judging by the face, Simon is relaxed/suspicious (ambiguity is intended). The ears, however, are a remarkably communicative and attractive component.

Photo credit: Georgia Institute of Technology; www.simontherobot.com

These are probably the safest designs for a Social robot in terms of reliability, convenience, and standardization (i.e., they all look the same). One can defend the benefit of making a robot that people expect to see because expectation is a powerful psychological force associated with positive reactions. I understand eliciting positive associations that come with familiarity, expectation, and so on; I also think there are unrealized and very important advantages to making Characters.

\section{Work Machines vs. Characters and Companions in HRI}

The four traits of Character robots are sometimes in opposition to the current norms of Social robot design, as described in Table 2.

Table 2 - Social Robots Often Fall Short of Being Characters

\begin{tabular}{|l|l|}
\hline Four Traits of a Character & Current Design Norm for Social Robots \\
\hline Biological appearance & $\begin{array}{l}\text { Non-biological, perhaps to impress, or to } \\
\text { comfort with the familiar "robot look, or to } \\
\text { appear soothing in the same way as hospital } \\
\text { machinery. }\end{array}$ \\
\hline Clear and simple in its expression & $\begin{array}{l}\text { Interaction complexity increases as a result of } \\
\text { an enhanced feature set. More mechanically } \\
\text { intricate embodiment is more easily confusing } \\
\text { in its non-verbal communication. }\end{array}$ \\
\hline Animated well & $\begin{array}{l}\text { Movement is crisp and precise, which is not } \\
\text { very good for animation. A cartoon character } \\
\text { moving in this way would probably only be } \\
\text { doing so while imitating a robot. }\end{array}$ \\
\hline Recognizable personality & $\begin{array}{l}\text { No recognizable personality. It is accepted that } \\
\text { the robot comes with standard software. } \\
\text { Robots are often passive and reactive. }\end{array}$ \\
\hline
\end{tabular}


The robots that are often used in HRI research would be classified as Work robots rather than Companion robots. Once we can distinguish our emotional bonds to Characters from our "function-only" relationship with other robots, then we can usefully reevaluate the types of robots we use for HRI research.

Apparently, HRI research is typically carried out with mostly semi-Characters: somewhat impersonal machines. This means that we are often doing work with "social" agents that carry very little social weight!

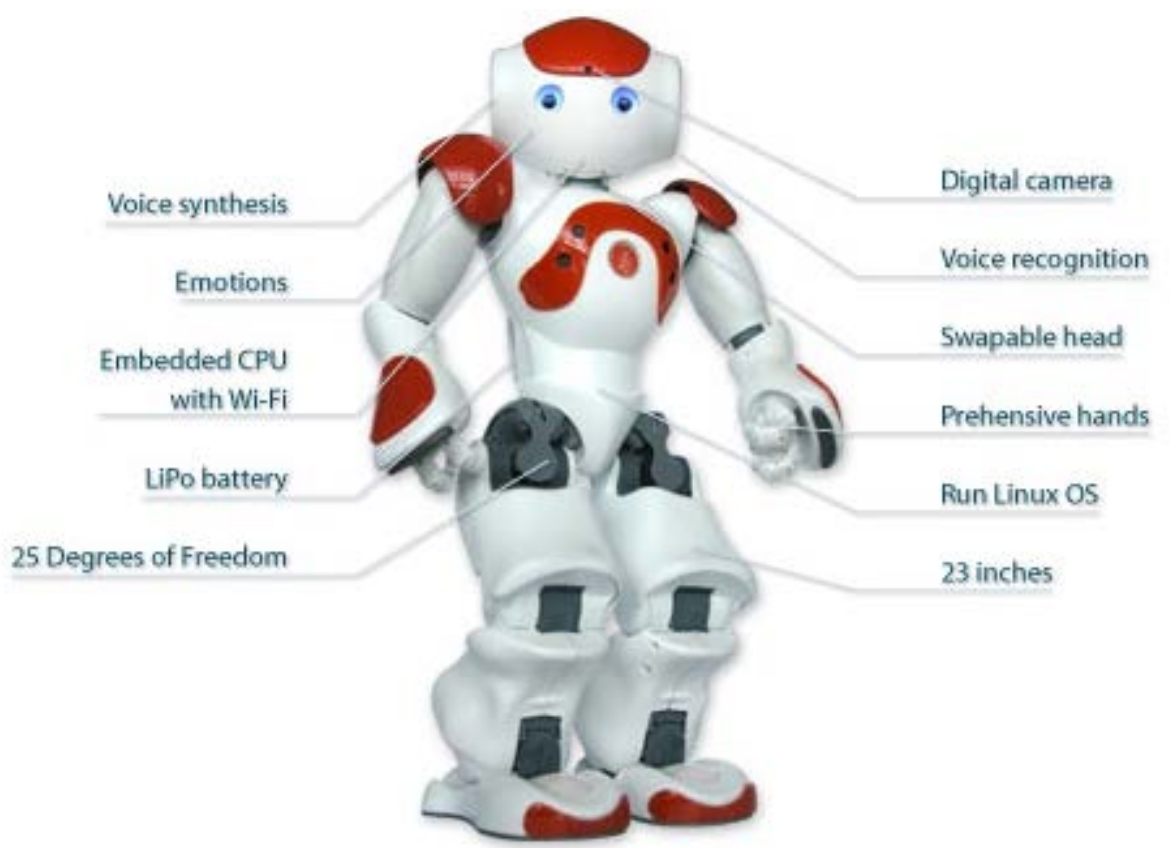

Figure 4. Aldebaran Robotics' Nao (Aldebaran Robotics, 2008).

Nao, as shown in Fig. 4, has a large feature set; I think this allows it to function well as a robot for experimentation, but it is definitely a robot and not a Slave. My social bond is weak with this platform. If you asked me to choose between pulling the tail of my darling cat and kicking a Nao into a bonfire, I would be sure to pick up my cat first so that she doesn't get too scared of the refueled fire.
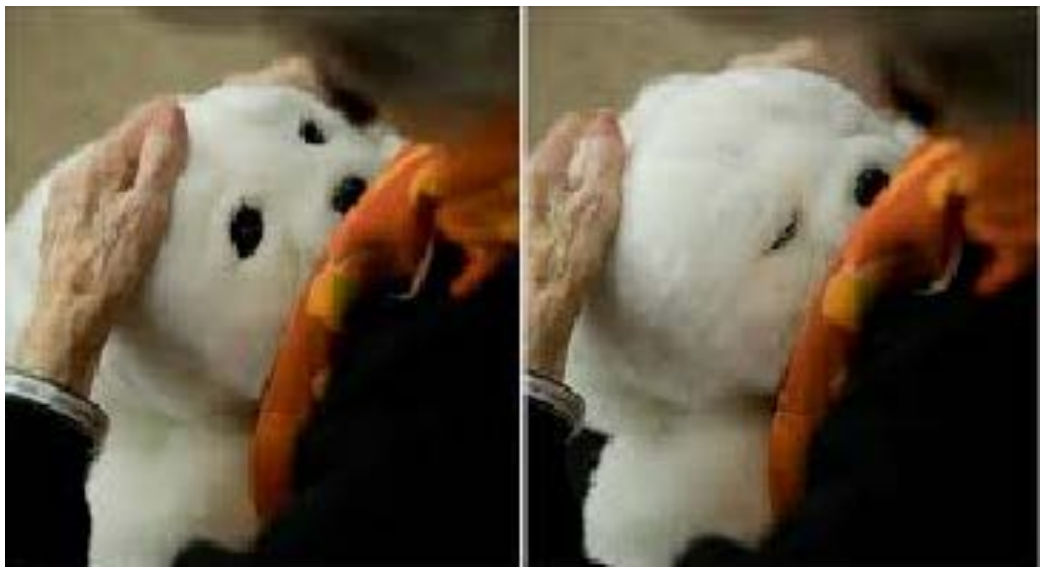

Figure 5. Paro. Photo credit: Stephen Crowley, The New York Times (2010). 
Paro is a good Character in the Work typeology. It uses creature special effects and principles discussed in this paper. This is an Entertainment robot performing valuable work, so it is a Companion Slave. It is, in my opinion, one of the most effective platforms at modifying human affect. I had a warm emotional response even just from observing people interact with Paro, as in Fig. 5.

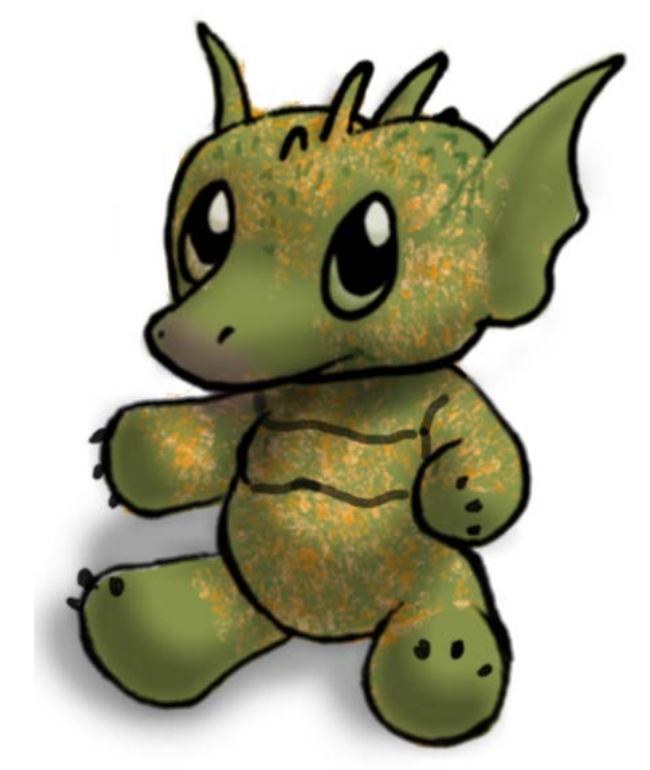

Figure 6. One of Dozens of Concept Drawings for Therabot. Image credit: Golem Group, LLC.

Therabot is a robot platform that my company has been designing and building for over a year. It is part of a two-year grant given to Professor Cindy Bethel to explore the use of robots in medical therapy sessions. I am attempting to apply many of the principles outlined in this paper with Therabot. Therabot would probably fit into the same class as Paro.

It is worth noting that Therabot was designed in part by potential users by way of an online survey. This is an example of participatory design, which I believe has strong potential as a developmental tool for robot designers and engineers.

\section{The Four Traits of a Character Robot}

This is the central offering of this essay. I believe that a better execution of these four traits in Social robot development will lead to real Companions: Characters that we bond with as they work with and alongside us.

To better illustrate these four traits of a Character, I have given scores ( 0 to 1$)$ to some robots and Characters. For each table, my scoring criterion will be one of the four traits of a Character. To avoid alienating friends and colleagues, let me say that I have selected a personal favorite Character to serve under both columns.

\section{Character Trait 1: $\quad$ Biological Indicators}

Table 3 - Biological Indicators of Humanoids/Substance Below the Skin 


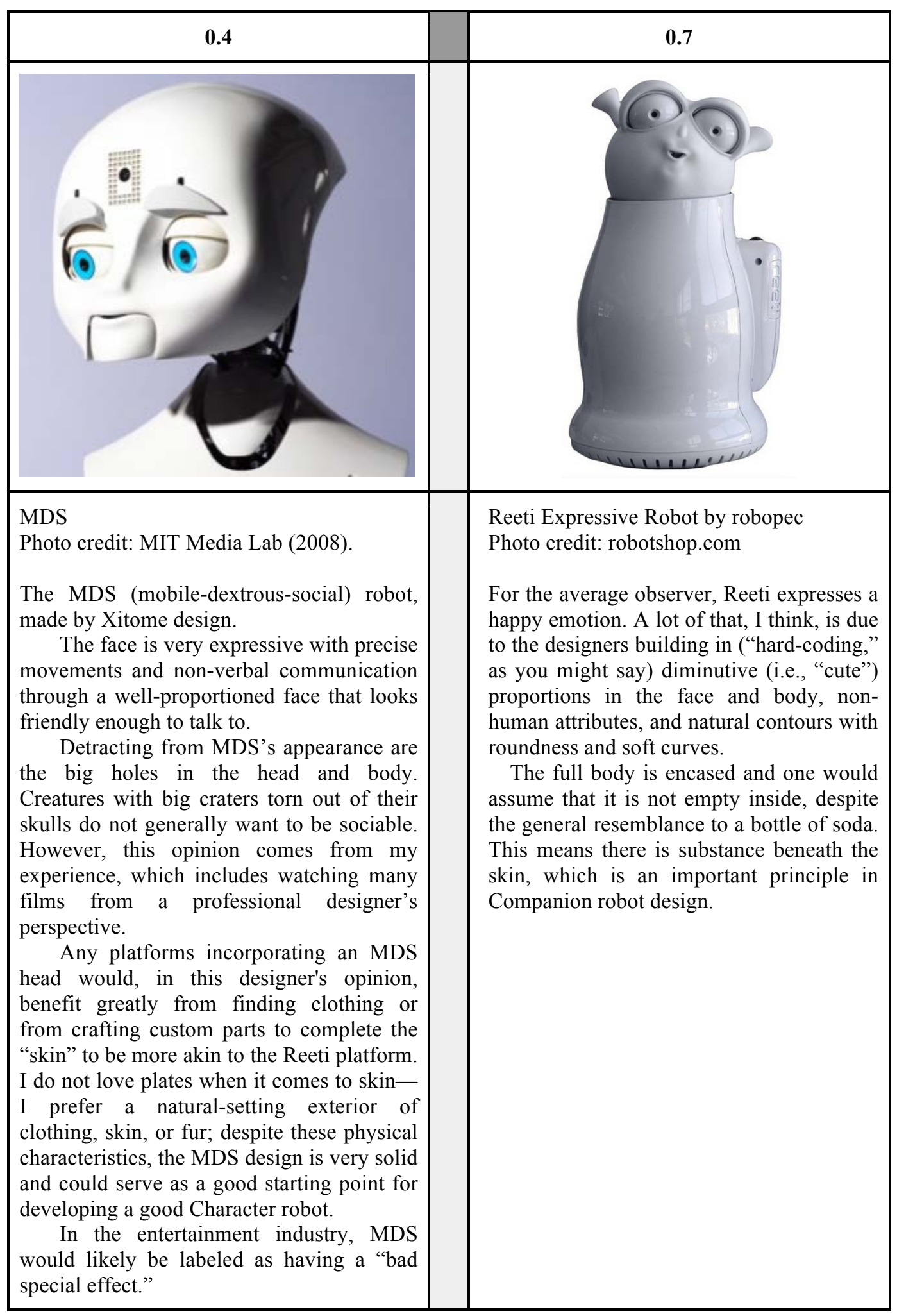


Table 4 - Biological Indicators of Animals

\begin{tabular}{|c|c|}
\hline 0.3 & 0.9 \\
\hline $\begin{array}{l}\text { Cute Aliens } \\
\text { Galaxy Quest (Johnson, Newirth, \& Parisot, } \\
\text { 1999) } \\
\text { The Leonardo robot, created by Cynthia } \\
\text { Breazeal, the MIT Personal Robots Group, } \\
\text { and the Stan Winston Studios effects team } \\
\text { (2002), inspired me to change my career. } \\
\text { They did effects for Galaxy Quest, which } \\
\text { was supposed to be about real aliens. The } \\
\text { practical effects (robots, animatronics, } \\
\text { puppets, makeup, etc.) are very artificial, in } \\
\text { my opinion, and these aliens are clearly } \\
\text { cartoons. Cartoons undoubtedly have no } \\
\text { biological substance. } \\
\text { Additionally, the skin and its shine } \\
\text { effects are too perfect, the aliens all look } \\
\text { identical, the light and shadows do not look } \\
\text { correct in terms of reflected light from the } \\
\text { nearby ground and other objects, and so on. } \\
\text { Computer graphics capabilities are } \\
\text { amazing and continue to get better, but I } \\
\text { personally hope that misuse and overuse of } \\
\text { computer graphics diminishes. This is in } \\
\text { part because I want to make creatures for } \\
\text { The Dark Crystal (Henson, Kurtz, \& Oz, } \\
\text { 1982), should it ever be produced! I think } \\
\text { there is some chance of animatronics in } \\
\text { filmmaking a comeback: "[There] seems to } \\
\text { be a little resurgence in animatronics; I } \\
\text { think everyone is sick of looking at } \\
\text { cartoons." } \\
\text { - Dan Burnett, film technician. Innovated } \\
\text { animatronics work on Lost in Space (1998), } \\
\text { Charlie and the Chocolate Factory (2005), } \\
\text { and other films. }\end{array}$ & $\begin{array}{l}\text { Leonardo, "Leo" } \\
\text { Photo credit: Stan Winston Studios \& MIT } \\
\text { Media Lab Personal Robots Group; } \\
\text { http://robotic.media.mit.edu/projects/robots/ } \\
\text { leonardo/overview/overview.html } \\
\text { In this author's opinion, Leonardo is the } \\
\text { most well-executed creature effect in an } \\
\text { HRI platform. Biological indicators for an } \\
\text { animal are plentiful in this design. The } \\
\text { illusion of life is obvious in the body, fur, } \\
\text { and face. Leo inspired me to get into this } \\
\text { field and abandon a career in military } \\
\text { robotics. } \\
\text { This impressive research platform was } \\
\text { produced by a group renown for puppetry } \\
\text { and animatronics in the Terminator Series, } \\
\text { Iron Man, Jurassic Park, AI, and so on. } \\
\text { The aliens shown to the left avoid the } \\
\text { Uncanny Valley (Mori, 1970) by being } \\
\text { sufficiently non-human; I think they are } \\
\text { perceived as fake because they are not } \\
\text { physically real. } \\
\text { After watching video of Leo, I have no } \\
\text { doubt that he physically exists in the same } \\
\text { world that I do. This may not seem very } \\
\text { profound, but I suggest that this physical } \\
\text { and digital misalignment may be part of the } \\
\text { reason for computer animated humans often } \\
\text { landing in the perceptual Uncanny Valley } \\
\text { (Mori, 1970). }\end{array}$ \\
\hline
\end{tabular}


Plush toys, cartoons, and puppets imply bone, ligaments, flesh, or some other substance below the skin, despite the additional effort this requires in creating the illusion of the Character. When Tex Avery and company came up with Bugs Bunny, they could put pencil to paper and literally draw anything, but they restricted themselves to skin with fur, musculature, jointed bones, and so on. I think they restricted themselves to anthropomorphic animals and exaggerated humans because our important interactions in life are with biological organisms. Creature effects are achieved with the implication of muscles pulling on skin, which leads to wrinkles that create expressions rather than hinged plates or obvious robotic joints for articulation. I think we should not show off the electromechanical clockwork if we want to make the robot seem more than mechanical bits and software.

Technique: Creature skin

In animatronic creature effects, a skin is made using something similar to mask-making techniques: a clay sculpture is captured with an inner and an outer mold. These molds are made of gypsum or another of the various types of plaster. Gypsum works well for a latex (rubber) mask. Liquid latex (mixed with ammonia) is poured into the mold cavity and after some ammonia and other liquids evaporate away, the solid rubber is removed.

\section{Technique: Mechanical core}

After a skin has been produced, a mechanical core (thin plastic shell, also called "underskull") is produced to fit the exact form of the inside skin surface. The mechanical core is chopped up and modified to simulate bones and muscle, motors are fastened to it, and it can then push the skin around with precision. This is a cursory view of a complex technique, but it provides a good sense of how highly emotive Characters have been made with methods substantially different from standard robotics engineering.

This technique and its adaptations are extremely pervasive. All but three of the robots and physical Character effects (non-cartoon) shown in this essay have implemented some form of a mechanical core. 
Character Trait 2: Simple Embodiment With Exaggerated Expression

Table 5 - Face Simplicity and Expressiveness

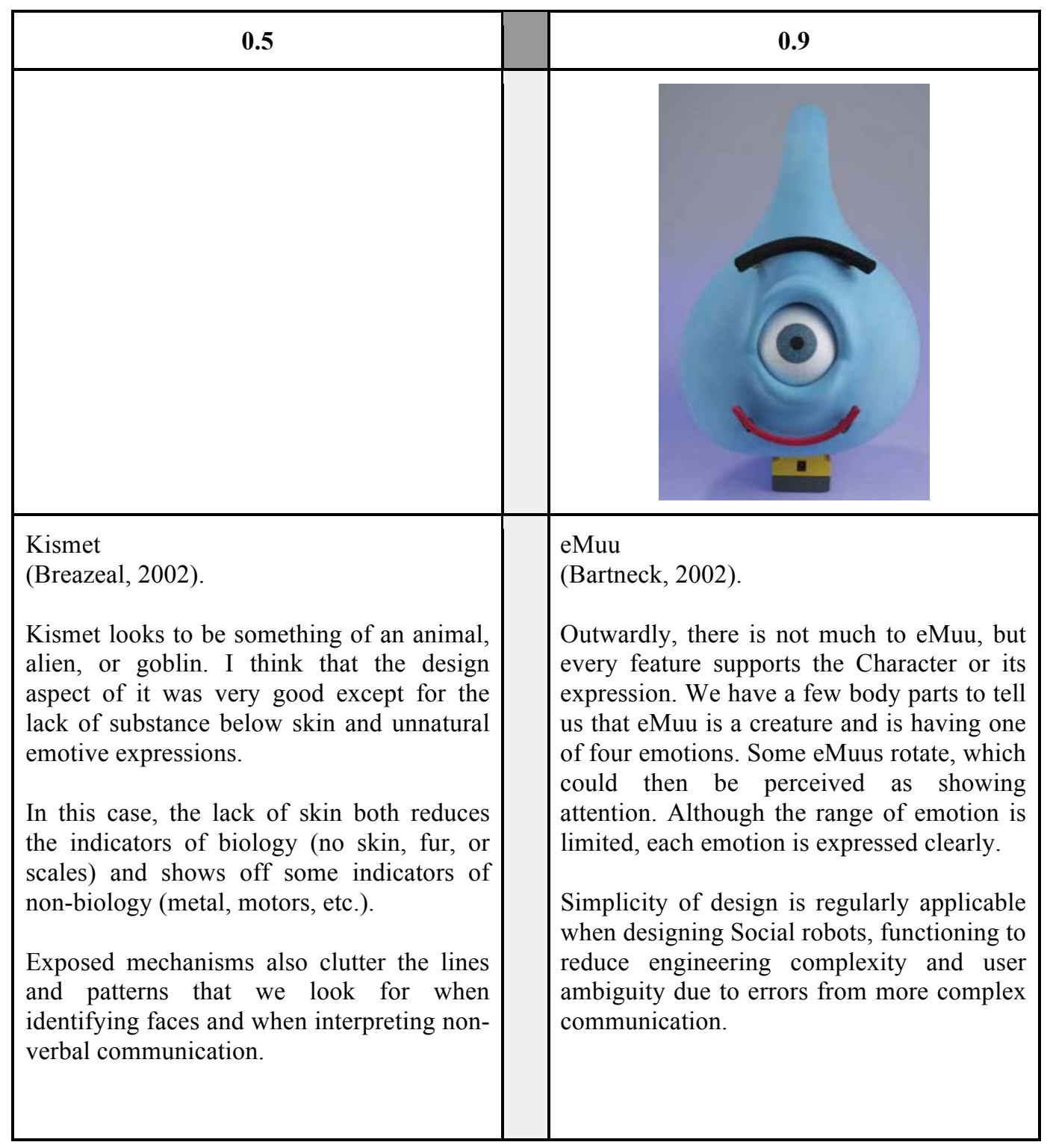


Table 6 - Body Simplicity and Expressiveness

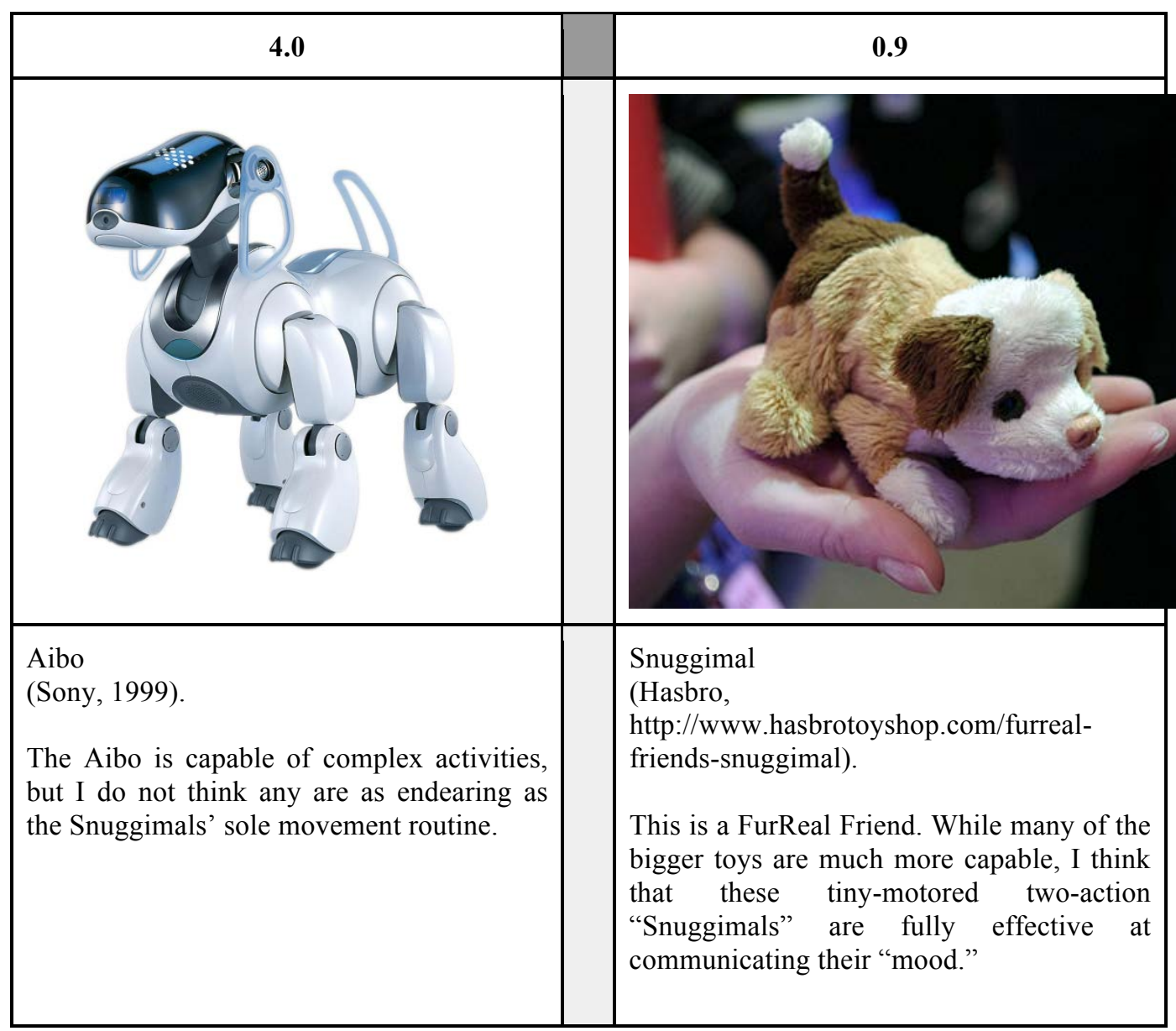

Effects design principles discussed thus far include more general than practical effects. For instance, making simplified robots like those shown in the above tables hearkens to the simplification of computer graphics - even when the technology could make it more richly textured and realistically shaped. Most computer graphics films use cartoonish qualities in their synthesized Characters.

The realistic synthetic representation of a human face could often be described as being in the Uncanny Valley (Mori, 1970). Most readers, I would expect, would more easily relate to the outer two Characters of Fig. 7 than they would the more realistically rendered cartoon as depicted by the center Character.

When we, as designers, use animation to communicate the intent, personality, and other salient features of the robot, we are performing the same task that cartoonists, puppeteers, video game developers, and animatronics technicians have done for decades. The common thread among designs from these industries is that a Character's embodiment and non-verbal communication are simple, clear, and exaggerated. 


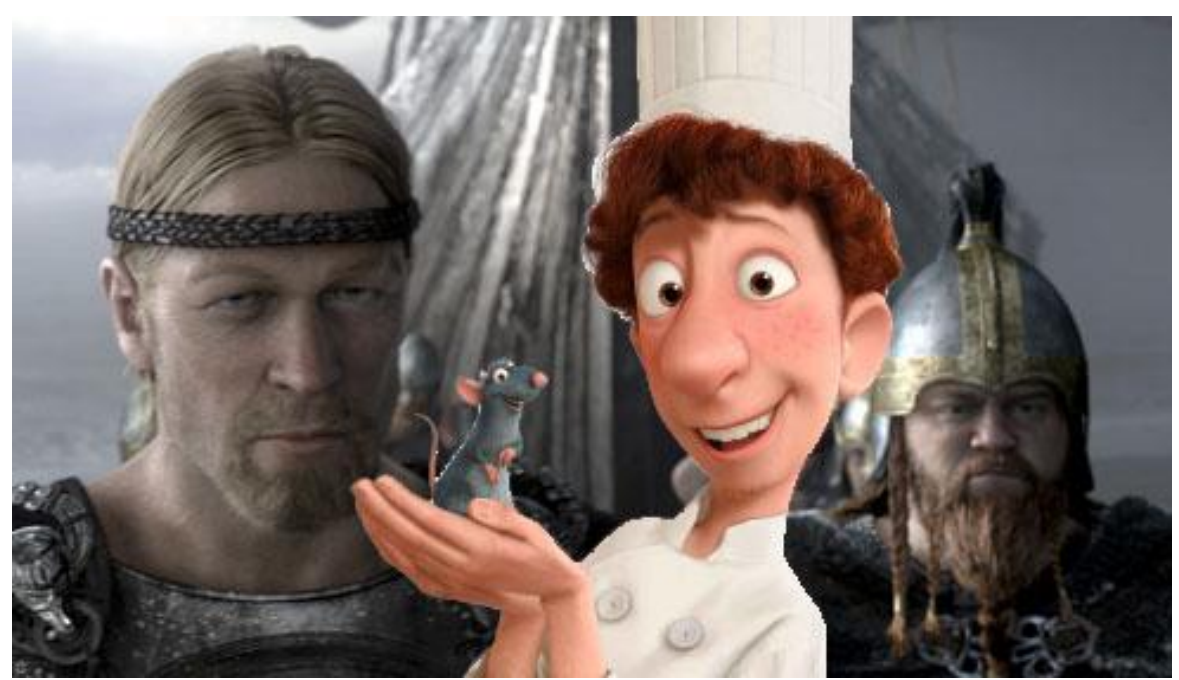

Figure 7. A comparison of styles in computer graphics. Photo credit: Golem Group, LLC: Beowulf (2007, Motion Picture) \& Ratatouille (2007, Motion Picture).

\section{Character Trait 3: Better Animation}

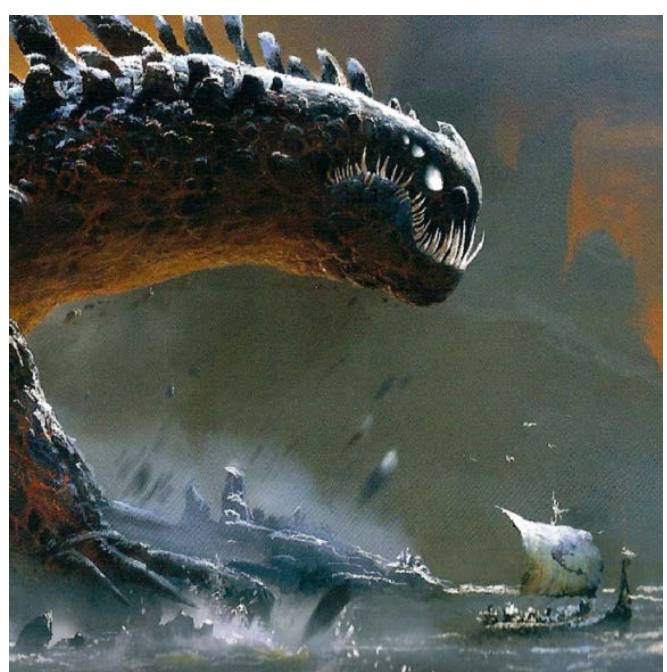

Figure 8. Artist concept of a theoretical non-ideal human-robot interaction session

Photo credit: WallpapersWide; http://wallpaperswide.com/how_to_train_your_dragonwallpapers.html 
Table 7 - Creature Animation

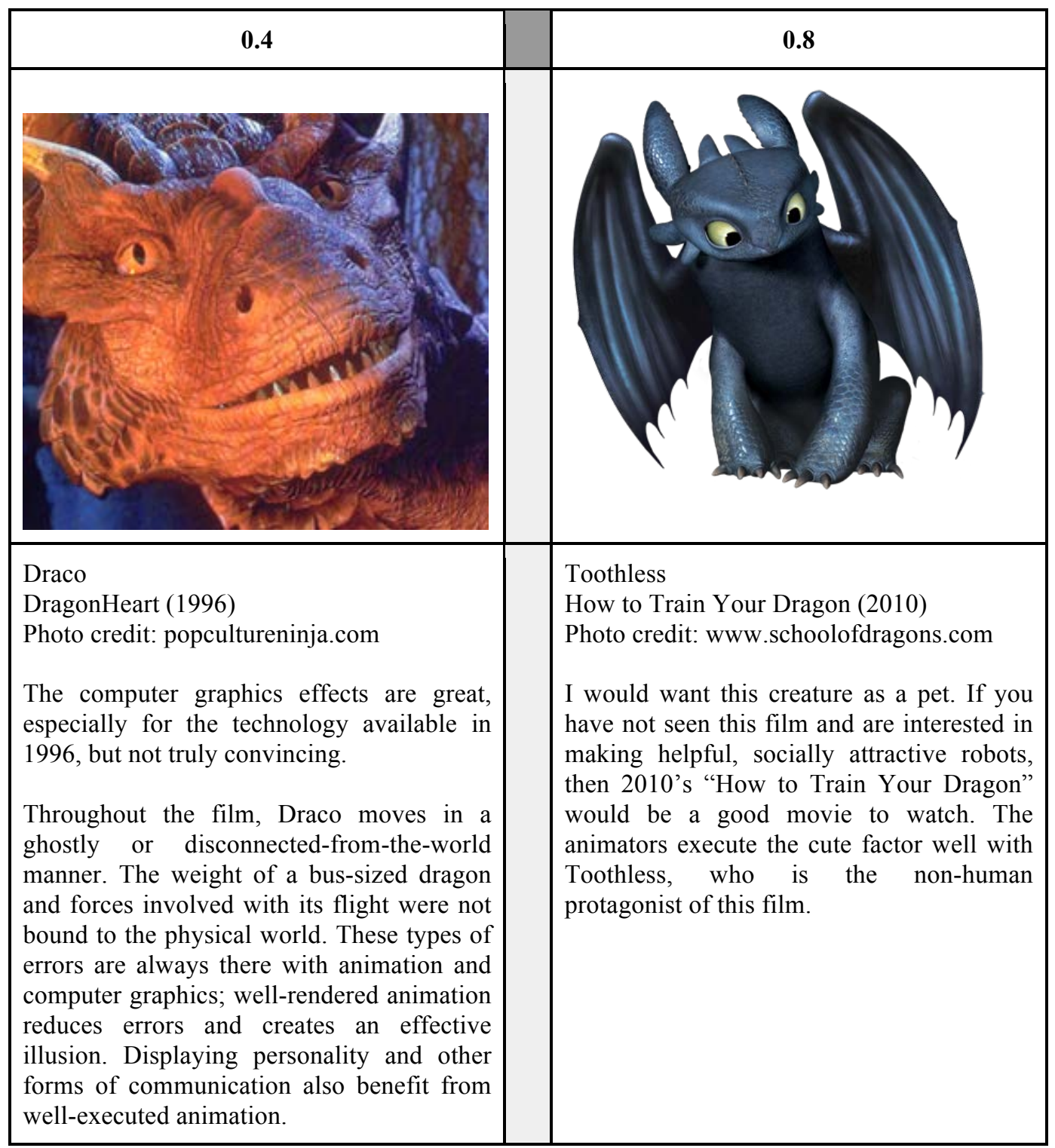

Fig. 8 is the "How to Train your Dragon" creature effect done in the style of the "Heroic and Friendly Dragon" creature style of Dragonheart. As the scene suggests, a realistic form of a creature is not always ideal.

Digital illustrators are regularly able to better project character and personality into their basic puppets and cartoons than is normally seen in typical HRI platforms. The industries of modern digital film effects and modern animatronics are so astounding, I think, because these artistic industries have laboriously figured out how to effectively animate. They have learned to make Characters.

We can observe how the entertainment industry has handled their Entertainment robots that must be animated as Characters. A clunky robot Character like C-3PO can handle a few minutes of screen time, but if you want a Character to carry scenes, it takes something like Harry (of the Hendersons), Gollum (of Lord of the Rings, 2001-2003), or Kermit, i.e., something capable of a wide variety of articulations. 
Character Trait 4: Recognizable Personality

Table 8 - Personality Development

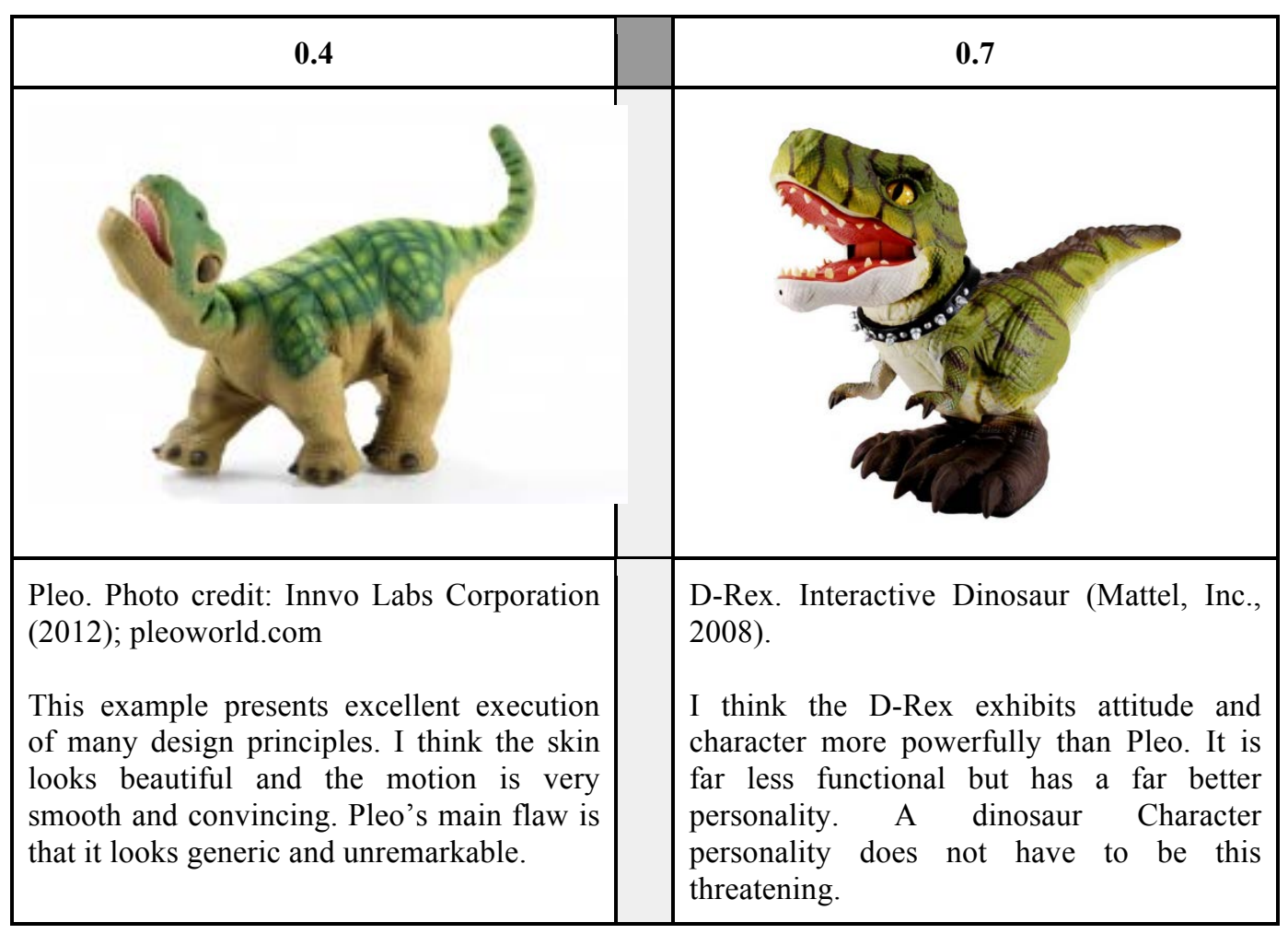

It has been demonstrated that giving robots particular or more cartoony personalities can have positive effects on a human observer (Walters, Syrdal, Dautenhahn, te Boekhorst, \& Kheng, 2008). This benefit can be better realized by exaggerating aspects of the robot's behavior and appearance to highlight the illusion that there is a recognizable and somewhat distinct mind behind it all.

Mickey Mouse is a Character that has stood the test of time; he is one of the most recognizable images for most people, even now, more than 80 years since his debut. When Donald Duck came on the scene a few years after Mickey, he similarly settled into the public consciousness. The reason people can accept these two cartoon characters - and many more beside them - is that they are such different characters.

If your neighbors somehow obtain a dozen exact duplicates of your own dog, even in how the dogs treat you, then I would expect your relationship with your dog to change for the worse. Like Mickey and Donald, your dog and someone else's dog have their own looks and personalities, and therefore fill a different place in your mind. The recognizable personality of a Character enhances the interaction we have with it by providing novel perspective, surprises, and significance.

Perhaps, with each having a unique personality, we will someday see a multitude of Companion robots in the marketplace. If one robot shows a snide attitude while another is more cheerful, surely there are people out there who will prefer each of them for exactly that attribute making the robot unique. The dimensions of a Character are numerous, but fortunately so are the reasons we have for liking things. 


\section{Conclusion}

Perhaps unfortunately for us, the engineers and scientists, the pursuit of goals examined in this paper will involve more artistry. The best way to reach good designs is through finessing them to perfection, and by iteratively and intelligently improving designs over time. If you have ever tried to design something just to be aesthetically pleasing, then you know it can be time-intensive and frustrating; it can seem like nothing is working and then, hopefully, the design reaches cohesive completion. Designers in the entertainment world, with its focus on creating human experiences, will keep developing and enacting ideas until they resonate. We can theorize about why one smartphone game is wildly successful while a hundred similar applications are flops, or why the same happens with television shows, music, and other forms of artistry; but even informed predictions about what will thrive are often wrong. The only product that is almost guaranteed to be unremarkable is a copycat of whatever currently has the market captured; this gives us license, if not a mandate, for originality as we work on Character robots.

For most people, interaction with robots is a rare occurrence-and with what I have been calling "Slave" robots, the interactions currently appear restricted to people who like gadget toys, science fiction, and amusement parks, as well as robotics engineers who like them all and turn this into their careers. However, all the signs of marketing, technology development, desirability and more are pointing toward HRI continuing to change in a big way. These interactions will likely become as requisite as are our interactions with smartphones and hand tools today, so designing these interactions to be successful and sustainable is paramount.

The four traits I have described above are how I suggest we start. With this vision, the Companion type of robot benefits by also being a Character. The Character robot is biological in appearance, clear and simple in its embodiment and expression, well-animated, and recognizable by its great personality. Each of these four Character traits has been essentially mastered in the realm of $2 \mathrm{D}$ and $3 \mathrm{D}$ cartoon animation, puppetry, animatronics, and other entertainment technologies. Character robots come from converging modern robot science and engineering with Character design from the aforementioned technical, but also artistic, fields.

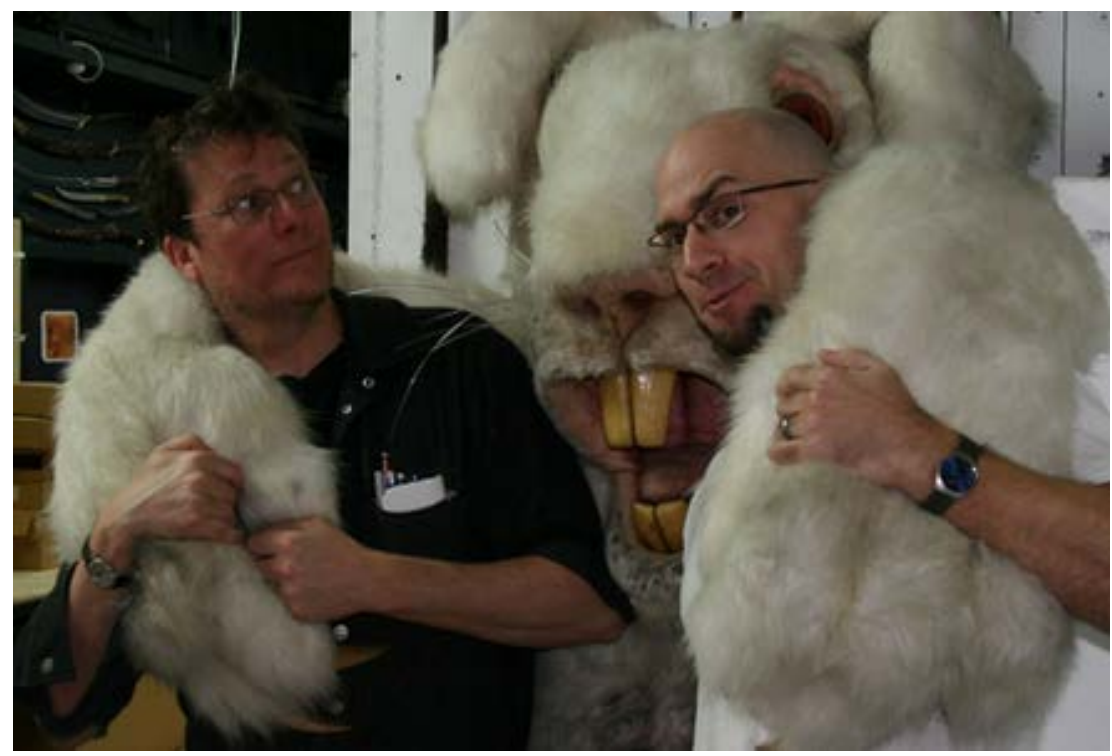

Figure 9. The author with a Character (center) and Richard Taylor (left), owner of Weta Workshop and the person most responsible for the special effects seen in the Lord of the Rings film trilogy (2001-2003). Photo credit: Golem Group, LLC.

I suggest exploring the friendly creatures from fantasies and myths, both new and old. Our need for entertainment has opened the door to creating pet robots, friendly aliens, talking animals, and other Characters. These imaginative fantasies, yours and those of others, may lead to a nearly ideal Companion for each of us. Mine, I think, would be Kermit. 


\section{References}

Aldebaran Robotics [Company] (2008, October 27). Aldebaran Robotics' NAO Humanoid Bends Over, Squeezes Duck. BotJunkie. Retrieved from http://www.ackdigital.com/botjunkie/ pages/Aldebaran_Robotics_NAO_Humanoid_Bends_Over_Squeezes_Duck.html

Aeryon Robotics [Company] (2009). Aeryon Scout micro-UAV. Retrieved from http://www. aeryon.com/products/avs.html

Bartneck, C. (2002). eMuu - An embodied emotional character for the ambient intelligent home. (Thesis: Doctor of Philosophy). Eindhoven, Netherlands: Eindhoven University of Techology.

Blomkamp, N., Block, B., \& Kinberg, S. (Producers) \& Blomkamp, N. (Director) (2013). Elysium [Motion Picture]. United States:

Breazeal, C. (2002). Designing Sociable Robots. Cambridge, MA: MIT Press.

Charles, Ray (1975). It's not easy being green. [Album, LP out of print]: Track 7, Renaissance.

Cooney, J. G. (Producer) (1975, September 7). Sesame Street [Television series episode]. United States: Public Broadcasting System.

Cunningham, C., Weiner, Z., Walsh, F., \& Jackson, P. (Producers) \& Jackson, P. (Director) (2012). The hobbit: An unexpected journey [Motion Picture]. United States: Warner Bros. Pictures.

De Laurentiis, R. (Producer) \& Cohen, R. (Director) (1996). Dragonheart [Motion Picture]. United States: Universal Pictures.

Groening, M. \& Cohen, D. X. (1999). Futurama [TV Series]. United States: Fox.

Henson, J. (1976). The Muppet Show [TV Series]. England: ATV Elstree Studios.

Henson, J., \& Kurtz, G. (Producers) \& Henson, J. \& Oz, F. (Directors) (1982). The Dark Crystal [Motion Picture]. United States: Universal Pictures.

Johnson, M., \& Newirth, C. (Producers) \& Parisot, D. (Director) (1999). Galaxy Quest [Motion Picture]. United States: DreamWorks Pictures.

Kahn, P. H. Jr., Kanda, T., Ishiguro, H., Freier, N. G., Severson, R. L., Gill, B. T., Ruckert, J. H, \& Shen, S. (2012). Robovie, you'll have to go into the closet now: Children's social and moral relationships with a humanoid robot. Developmental Psychology, 48(2), 303-314.

Mori, M. (1970). The uncanny valley. Energy, 7(4), 33-35.

Spielberg, S. (1984). Gremlins [Motion Picture]. United States: Warner Bros. Pictures.

Tei (2012, February 8). Human-Robot Interaction: Introduction. Retrieved from http://humanrobotinteraction.org/1-introduction

Turkle, S., Taggart, W., Kidd, C.D., \& Dasté, O. (2006). Relational artifacts with children and elders: The complexities of cybercompanionship. Connection Science, 18(4), 314-361.

Walters, M. L., Syrdal, D. S., Dautenhahn, K., te Boekhorst, R., \& Kheng, L. K. (2008). Avoiding the uncanny valley: Robot appearance, personality and consistency of behavior in an attention-seeking home scenario for a robot companion. Autonomous Robots, 24(2), 159178.

Author's name and contact information: Derek Scherer, derekscherer.com. Golem Workshop:

Golem Group, LLC, Overland Park, KS, USA. Email: derek@derekscherer.com 